\title{
In-Class Team Design Competitions - The Mechatronics Example
}

\author{
Brian Surgenor*, Ridha Ben Mrad** and Kevin Firth* \\ *Dept. Mechanical and Materials Engineering, Queen’s University, Kingston \\ surgenor@me.queensu.ca \\ **Dept. of Mechanical and Industrial Engineering, University of Toronto, Toronto \\ rbenmrad@mie.utoronto.ca
}

\begin{abstract}
External team design competitions continue to be popular with students, from Formula SAE racing to Sunrayce Solar vehicles. It is generally accepted that the hands-on design, build and test activities inherent with these projects provide students with invaluable experience for their future careers as engineers. In this paper, examples of two in-class team design competitions are given. Both examples are mobile robot based competitions held in courses in mechatronics engineering as offered by instructors in mechanical engineering. It is claimed that the in-class competitions have similar benefits to external competitions, but have a greater impact as they involve more students.
\end{abstract}

\section{Introduction}

For well over a decade, engineering educators have been extolling the benefits of external design competitions, with Formula SAE racing [1] and the Sunrayce Solar [2] vehicles being two examples with fairly high profiles. It is generally accepted that the hands-on design, build and test activities inherent with these projects provide students with invaluable experience for their future careers as engineers [3]. The majority of projects are student led and extra curricular. There is a long standing debate over whether or not these projects should be formally incorporated into the undergraduate curriculum. The resistance stems from the belief that the highly creative nature of the projects, together with the long hours that students invest in their designs, would end as soon as the project became course driven. Most schools adopt a compromise, whereby components of the projects appear in the senior year capstone design course. The debate has renewed in recent years over rising concerns with respect to student safety, together with the higher costs associated with support of the projects. However, the purpose of this paper is not to revive this debate, but to give two examples of in-class team design competitions. Both examples are mobile robot based competitions held in fourth year courses in mechatronics engineering as offered by instructors in mechanical engineering, one at Queen's University and the other at the University of Toronto.

When it comes to external team design competitions involving autonomous mobile robots, in North America the preeminent events are considered to be the IEEE Micromouse Contest, the AAAI Mobile Robot Competition and the RoboCup Robot Soccer Competition [4]. However, it is also fairly common to conduct mobile robot competitions as part of an electrical engineering curriculum [5] or as part of a first year engineering course [6]. It is claimed that the in-class competitions have similar benefits to external competitions, but have a greater impact as they involve more students .

\section{Mechatronics at Queen's University}

The Mechatronics Concentration as offered by the Department of Mechanical and Materials Engineering at Queen's University consists of seven recommended elective courses to be taken by students in their third and fourth year of study:
1. Computer Architecture
2. Microprocessor Systems
3. Computer Integrated Manufacturing
4. Introduction to Microsystems
5. Introduction to Robotics
6. Machine Condition Monitoring
7. Mechatronics Engineering 
The first three courses are offered by Electrical Engineering and the remaining courses are offered by Mechanical Engineering. The course Mechatronics Engineering or MECH 452 is the subject of this paper.

The majority of students taking MECH 452 are in their final year of a degree in mechanical engineering. There are also students from engineering physics and engineering mathematics. All students will have had earlier courses in design, electronics and computer programming. The objective of the course is to extend their working knowledge of engineering to include applied electronics and microcontroller programming. The course does not cover the full range of computing, electrical and mechanical engineering topics that typically come under the heading of mechatronics engineering. But experience has shown that it does succeed in sensitizing students to issues associated with the design of mechatronic systems

MECH 452 is designed around a series of laboratories that involve a prototyping board, a microcontroller and a mobile robot. The laboratories are used to introduce the students to the microcontroller and different sensor technologies. Lectures are used to introduce the laboratories and to illustrate industrial applications of the technology. For the laboratories, students work in pairs, and this occupies the first nine weeks of the course. In the final three weeks of the course, the experience and knowledge gained in the laboratories is applied to a team design project that ends in a competition. Further details on MECH 452 can be found in [7].

The original robot used in the course was designed in-house in 1999 and had an easy to use platform on which sensors, actuators and associated circuits could be mounted. A sharp increase in board failures in the Fall of 2008 prompted a switch to a commercial mobile robot manufactured by LynxMotion (see Figure 1). The standard commercial model was modified for the needs of the course to include:

- Two separate batteries, 6 vdc for microcontroller and 12 vdc for motors

- Front bumper added with limit switches

- Rear bumper with external battery holder

- 10 LED based battery health indicator

- Motor driver board mounted inside the deck (not accessible to students)

- Microcontroller, protoboard and Lego on the deck (very accessible to students)

The chassis was originally marketed as a RadioControlled All-Terrain Vehicle (ATV). It was the robust "must be able to fall off of a table" criteria, that resulted in the selection of this particular chassis.

\subsection{Queen's Project and Competition}

The team design project conducted at the end of the course is used as the basis for the competition. The original version of the project, as illustrated in Figure 2, was posed as a problem that mimics a team of autonomous mobile robots trying to find and isolate multiple landmines (represented by lights). Three floor mounted lights were hidden behind three blinds. There were four openings in the blinds. A team of 10 students and 5 robots was tasked to find and cover the 4 openings. Each team was required to give an oral presentation on their solution to the problem. The nature of the task was such that it made use of all of the technology learned in the first half of the course. The students learn very quickly that one of the biggest problems is that of spurious and faulty sensor readings. The bulk of the design time is spent addressing this problem, typically by the application of redundant sensors in combination with innovative programming. This version of the project was run for 3 years, at which time it was judged time to switch to a new task, prompted in part by the introduction of a colour camera as one of the available sensors.

The second version of the project, as illustrated in Figure 3, was posed as a problem that mimics the task of autonomous vehicle navigation, with robots going in opposite directions on " 2 way streets". The test arena was rectangular, partitioned into streets, with robots starting in opposite corners, with red, yellow, green and blue balls as stationary targets. Each team of 8 students and 4 robots was tasked to drive from their start point to their designated colour target, without collisions. Robot mounted cameras were used to identify the colour of the target balls. This version of the project was run for 2 years, at which point the switch to the new version of the mobile robot prompted a third and current version of the project.

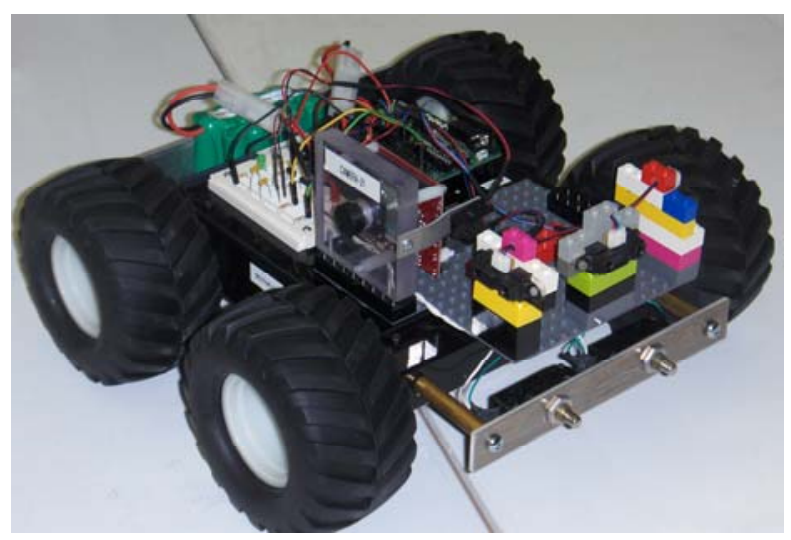

Figure 1. Robot for Queen’s mechatronics course. 
The current version of the project, as illustrated in Figure 4, is posed as a problem that also mimics the task of autonomous vehicle navigation, but with robots going in the same direction, in a classic "follow the leader" fashion. As this task is intended for the newer robots that are faster and mechanically more robust than the original robots, the test arena has a raised platform from which the robots can fall off. The team of 4 robots is tasked to travel around the loop continuously until the allotted time (nominally $10 \mathrm{~min}$ ) is up or one of the robots gets hung up. A red/green traffic signal (visible as green panel in the background of Figure 4) is used to regulate traffic. A colour camera on each robot is used to determine whether the signal is red or green.

Scoring is based on the performance of the robot team, the quality of the oral presentation and written report that each team submits to support their design solution. The project is conducted in 3 parts, with each part worth $10 \%$ towards the final mark in the course. Table 1 illustrates the robot scoring for Part 3, which is the "competition component" illustrated in Figures 2 to 4 . One notes that a penalty based scoring system has been adopted, in which each robot team is assigned a perfect score to begin with, then marks are deducted for any infractions such as colliding with another robot.

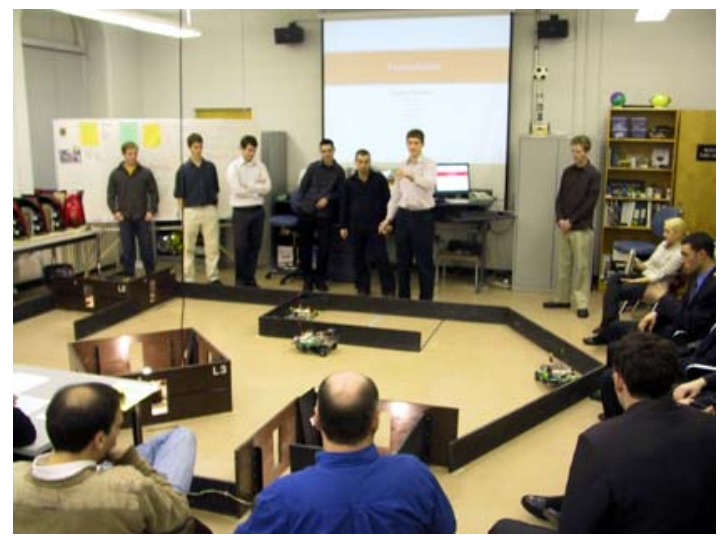

Figure 2. Original Queen's project "Search for Light”, with team presenting their solution.

\subsection{Experience with the Queen's Competition}

The evaluation of the final task is set up as a "competition day" with invited guests. This is an opportunity for the students to showcase their work and to let other faculty gain an understanding of the work being done in this particular course. Rather than have all of the marking ride on this competition day and to ensure a successful presentation, a trial demonstration is held the day before with only the instructors (and other students) acting as the audience.

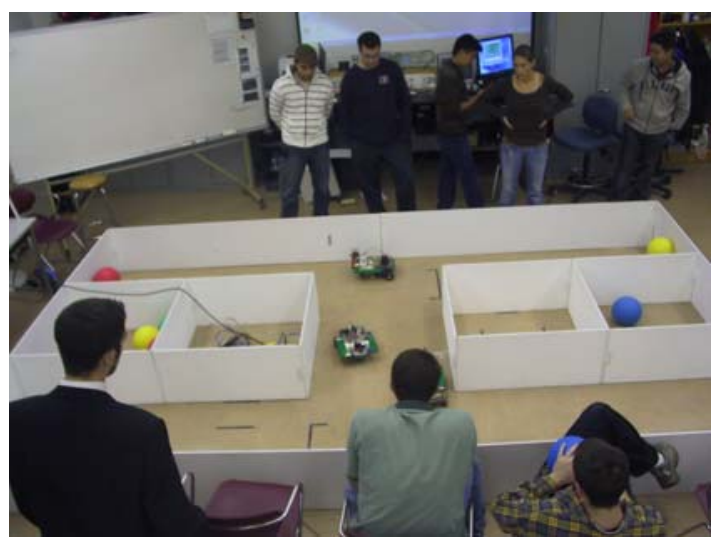

Figure 3. Second version of Queen's project "Search for Colour” with coloured balls as targets.

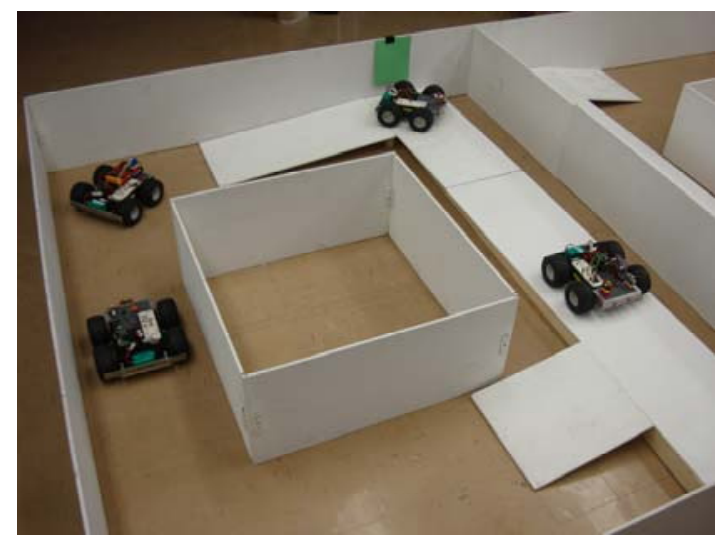

Figure 4. Current Queen's project "Navigating the Khyber Pass", with team of 4 ATV robots in play.

Table 1. Scoring for Part 3 of Queen’s project.

\begin{tabular}{|l|c|}
\hline \multicolumn{1}{|c|}{ Infraction } & Penalty \\
\hline $\begin{array}{l}\text { robot touches wall } \\
\text { (max 0.5 per robot) }\end{array}$ & 1 \\
\hline $\begin{array}{l}\text { robots touch each other (max 0.5 } \\
\text { per robot per shared touch) }\end{array}$ & 1 \\
\hline $\begin{array}{l}\text { failure to reach target } \\
\text { (0.5 per robot) }\end{array}$ & 0.5 \\
\hline $\begin{array}{l}\text { failure to pass each other at least } \\
\text { once when both in motion }\end{array}$ & 0.5 \\
\hline $\begin{array}{l}\text { not running on batteries } \\
\text { (either or both robots) }\end{array}$ & 4 \\
\hline \multicolumn{2}{|c|}{ maximum possible penalty } \\
\hline
\end{tabular}

maximum possible penalty 
Even though all of the elements of the final design task have been covered in earlier labs, the project makes students very aware of the systems engineering problems that crop up when assembling a large system from a number of smaller systems. For the competition day the teams are allowed a fixed amount of time to demonstrate and the clock cannot be stopped. Any changes or fixes must be done within the allotted time. This allows the start and finish times of the presentation to be scheduled. Each team has an announcer who explains to the audience what the robots are doing as they move through the test area. Most teams give a brief Powerpoint based presentation on their design, then provide 2 to 3 demonstrations of the ability of their robots to complete the assigned task, under different operating conditions.

\section{Mechatronics at University of Toronto}

The Mechatronics Stream as offered by the Department of Mechanical and Industrial Engineering at the University of Toronto was developed in order to lead to engineers with strong Mechanical Engineering design abilities. At the same time it contributes to their mastering the concepts of system modeling and analysis, analog and digital electronics, circuit design, motor and sensor integration and real-time control using microprocessors. All of these abilities are specifically covered in various courses offered to the Mechatronics Stream students. A special focus is integrating different technologies together and this is specifically pursued in two of the design courses offered in the fourth year.

The undergraduate curriculum at the University of Toronto is very flexible in the sense that it offers students the option to select more than one stream to follow with a stream being typically a sequence of three courses in a focused area. The Mechanical Engineering Program currently offers the following streams: Mechatronics, Solid Mechanics and Design, Bioengineering, Manufacturing, and Energy and the Environment. Students typically select two streams starting in the Winter Semester of the third year and they can opt out of a stream anytime. Streams offer a number of focused courses in their respective areas. The Mechatronics Stream specific courses are:

1. Analog and Digital Electronics for Mechatronics (Spring Semester $-3^{\text {rd }}$ year): A study of the fundamental behavior of major semiconductor devices.

2. Mechatronics Principles (Fall Semester $-4^{\text {th }}$ year): A presentation of the tools to design, model, analyze and control mechatronic systems. Analysis of the various components needed to design and control a mechatronic system including sensing, actuating, and I/O interfacing systems. A significant part of the course requirement is an integration project which would lead to the design and integration of an autonomous vehicle equipped with collision avoidance sensors.

3. Microprocessors and Embedded Microcontrollers (Winter Semester $-4^{\text {th }}$ year): A course focused on the design of embedded microcontrollers and interfacing circuits.

4. Mechatronics Systems: Design and Integration (Winter Semester $-4^{\text {th }}$ year): A course focused on designing and integrating a number of systems and implementing realtime controllers.

\subsection{Toronto's Project and Competition}

In the fourth year Mechatronics Principles and Mechatronic Systems courses the students are required to participate in design teams that will develop a solution to engineering problems. In Mechatronics Principles, for instance, the team takes the engineering problem from the conceptual stage to the prototype test stage. The class is ended with a competition. The design team is given a problem in the form of a Request For Proposal (RFP). The design team proposes a solution to the problem and if the solution is approved by the instructor and Teaching Assistants the team proceeds to build a prototype within the constraints of budget and time. The team members are expected to carry out all the tasks needed to ensure the success of their design/product including the purchase and machining of the required parts.

An example of an RFP was the development of a fully autonomous, electric-powered surface vehicle "Laboratory Rover" (see Figure 5). The rover is operated on a maze by following a white line and avoiding collisions (see Figure 6). The robot is expected to be fast, small and has the ability to turn. The students are asked to fabricate a "proof-ofconcept" prototype of the design they propose and to demonstrate it during a competition. In order to assist the students in developing their project, a series of labs are developed and students are asked to do them without submitting reports.

Typically there are 3 students per team per robot. The criteria used for project marking are technical accuracy, engineering insight, quality of the oral presentations, quality of the written reports, and quality and robustness of the fabricated robot prototype. Each member of the team is expected to 
take part in the oral presentations and contribute to the written reports. Each team is evaluated according to the division of points given in Table 2 . Teaching Assistants mark the students on all aspects of the project.

\subsection{Experience with the Toronto Competition}

One objective of the course is to have students learn to work in teams and to make frequent presentations to others about their progress. This is pursued as every student is required to present his/her own contribution to the project to the rest of the class at least twice during the semester. So far the feedback from students has been overwhelmingly positive. The fact that the course offers a number of labs run by Teaching Assistants and that are done throughout the term and that cover almost all of the basic skills needed to carry out the projects is very helpful to students. One aspect of the course is that it does not follow University of Toronto guidelines that require individual closely supervised work for every student to be at least $75 \%$ of the final mark of the course. Since this is a design and system integration focused course done in teams of three, these requirements were waived. Nevertheless, students are required to present orally and in writing their individual contributions to the project. The project accounts for $50 \%$ of the total mark of the course with the remaining 50\% being determined from a final exam and midterm test focused on the lecture material.

Another aspect of this course refers to the safety of students while working on these projects. This is especially critical in the last two weeks of the semester when students need to work outside of the regular lab hours to finalize and test their prototypes. To ensure that students are always working in a safe environment, a Teaching Assistant is hired to assist students during evenings (5 to $8 \mathrm{pm}$ ) and week-ends for the last two weeks of the term.

Table 2. Scoring for Toronto competition project

\begin{tabular}{|l|c|}
\hline \multicolumn{1}{|c|}{ Infraction } & Points \\
\hline Design proposal (week 7) & 20 \\
\hline Oral proposal presentation & 20 \\
\hline Propotype robot & 30 \\
\hline Oral competition presentation & 10 \\
\hline Final project report (week 13) & 20 \\
\hline
\end{tabular}

Total points

100

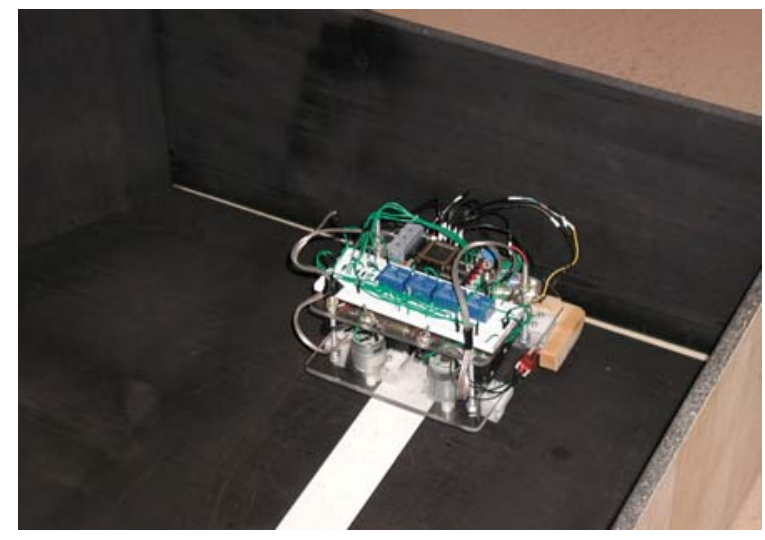

Figure 5. Robot for Toronto mechatronics course.

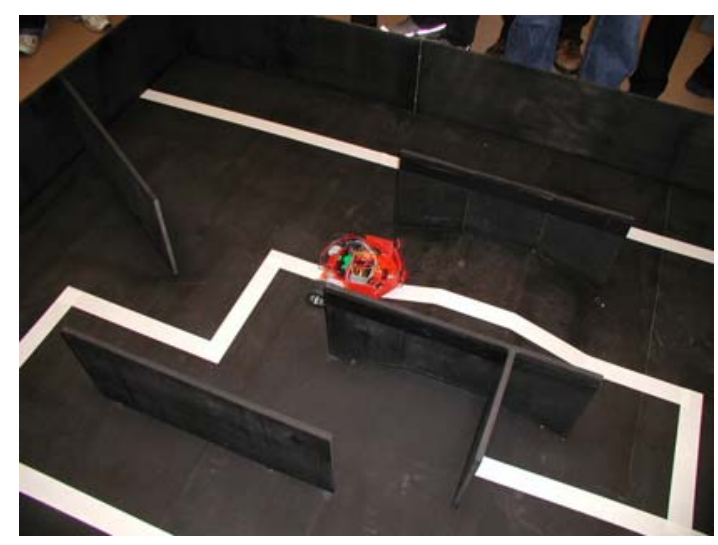

Figure 6. Maze for the Toronto competition.

\section{Other Schools}

A survey of European mechatronics courses reveals that the majority are laboratory-based [8]. Although mobile robots have regularly been used as a tool in electrical engineering programs, mechatronics has provided an opportunity to introduce such devices to non-electrical, and in particular, mechanical engineering students. That said, a recent survey of 15 mechatronics courses offered by Canadian Mechanical Engineering Departments found that only 10 are laboratory based. Of those 10 , only 5 used a mobile robot as the subject of a project. Of those 5 , only 3 used the project as the basis for a competition (Queen's, Toronto and Waterloo).

\section{Why a Competition?}

It is important to distinguish between two styles of competition. In one style, the objective of the competition is the defeat of the other competitors. In 
the second style, the objective is the defeat of a problem. The latter style is more conducive to teamwork, which has become an increasingly important element of an engineers education. Regardless of the style, a competition presents each student with a memorable example of a problem with more than one right answer, an exercise that is the essence of open ended design [3].

Some educators point out that students can be put off by competitions. Among the educators encouraging competitions, there is no general agreement as to what constitutes the best way of putting competitions to good use within an engineering curricula. As a general observation, some think that competitions need only be loosely coupled to the curriculum, and their role is to simply provide a break in the traditional model of material delivery. The idea here is that the beneficial effect of a competition derives precisely from the fact that it is a change from the regular curriculum.

Others argue that competitions are an effective way of motivating students and providing them with feedback and that, therefore, competitions should be based on the actual material taught in school, should be formally incorporated into the curriculum, and the competition results should be used to evaluate students (like an exam). Fun competitions (ones that usually involve an element luck and have rules that are open to interpretation) allow poor students to do well, thereby boosting their confidence. However, good students, who frequently like to have control over their marks, often dislike such competitions.

In spite of the contradictory opinions about the relevance of competitions to education and about how to conduct such competitions, it is our experience that the availability of good competitions is beneficial for education in almost any discipline. A good competition should challenge the participants to give their best, or preferably more than that. If the regular curriculum is not sufficiently challenging, then good students should be encouraged to participate in external competitions.

It is generally acknowledged that enthusiastic organizers are important to the success of a competition. However, it should be noted that organizing a good competition is a major challenge, which must not be underestimated. The three main phases for holding a competition are: 1) preparation, 2) execution, and 3) follow-up. The first phase is organization, the setting up and posting of competition rules, competition tasks and judging procedures. The rules should be as complete and transparent as possible, to avoid misunderstandings with the students. The second phase is where the actual competition is carried out, the students do the competing and are evaluated. In the third and final phase, the results are analyzed and feedback is provided to the participants, preferably as a group. Unfortunately, this last phase is often neglected. When the feedback is provided as a class discussion, useful information can be collected to improve on the competition for its next offering.

\section{Conclusions}

Two examples of in-class team design competitions have been given. Both examples were mobile robot based competitions held in courses in mechatronics engineering as offered by instructors in mechanical engineering. The in-class competitions have similar benefits to external competitions, but can be considered to have greater impact as they involve more students within a given school.

\section{References}

[1] J.J. Rencis. The Formula SAE Racecar Project at WPI. Proc. ASEE Annual Conference, St. Louis, Missouri, June 18-21, 2000.

[2] G.D. Catalano and K.L Tonso. The Sunracyce'95 Idea: Adding Hands-on Design to an Engineering Curriculum. Journal of Engineering Education, Vol. 85, No. 3, pp. 193-199, 1996.

[3] R.O. Buchal. The Educational Value of Student Design Competitions. Proc. $1^{\text {st }}$ CDEN Design Conference, Montreal, Quebec, July 29-30, 2004.

[4] T. Braunl. Research Relevance of Mobile Robot Competitions. IEEE Robotics \& Automation Magazine, Vol. 6, No. 4, pp. 32-37, 1999.

[5] R.R. Murphy. Competing for a Robotics Education. IEEE Robotics \& Automation Magazine, Vol. 8, No. 2, pp. 44-55, 2001.

[6] R. Freuler, M. Hoffmann, T. Pavlic, J. Beams, J. Radigan, P. Dutta, J. Demel and E. Justen. Experience with a Comprehensive Freshman Hands-On Course: Designing, Building and Testing Small Autonomous Robots. Proc. ASEE Annual Conference, Nashville, June 22-25, 2003.

[7] B. Surgenor, K. Firth and P. Wild. A Course in Mechatronics and Calling the Bluff on Active Learning. Proc. $2^{\text {nd }} C D E N$ Design Conference, Kananaskis, Alberta, July 18-20, 2005.

[8] Mr. Grimheden and M. Hanson. Mechatronics The Evolution of an Academic Discipline in Engineering Education. Mechatronics, Vol. 15, pp. 179-192, 2005. 